\title{
Retrospective evaluation of pathological results among women with ovarian endometriomas versus teratomas
}

\author{
MICHAIL MATALLIOTAKIS ${ }^{1,2}$, CHAROULA MATALLIOTAKI ${ }^{1,2}$, MARIA I. ZERVOU $^{3}$, \\ KONSTANTINOS KRITHINAKIS ${ }^{4}$, GEORGE N. GOULIELMOS ${ }^{3}$, IOANNIS KALOGIANNIDIS ${ }^{1}$, \\ AYDIN ARICI $^{5}$, DEMETRIOS A. SPANDIDOS ${ }^{6}$ and IOANNIS MATALLIOTAKIS ${ }^{2}$
}

\author{
${ }^{1}$ Third Department of Obstetrics and Gynecology, Aristotle University of Thessaloniki, Thessaloniki 54124; \\ ${ }^{2}$ Department of Obstetrics and Gynecology, Venizeleio and Pananio General Hospital of Heraklion, Heraklion 71409; \\ ${ }^{3}$ Section of Molecular Pathology and Human Genetics, Department of Internal Medicine, School of Medicine, University \\ of Crete, Heraklion 71003; ${ }^{4}$ Department of Gynecology, General Hospital of Agios Nikolaos, Lasithi 28410, Greece; \\ ${ }^{5}$ Department of Obstetrics, Gynecology and Reproductive Sciences, Yale University School of Medicine, New Haven, \\ CT 06520, USA; ${ }^{6}$ Laboratory of Clinical Virology, School of Medicine, University of Crete, Heraklion 71003, Greece
}

Received February 28, 2019; Accepted April 10, 2019

DOI: $10.3892 / \mathrm{mco} .2019 .1844$

\begin{abstract}
The coexistence of endometrioma with dermoid cyst of the ovaries is an unusual entity, although they are both common and benign gynecological tumors. The present study aimed to investigate the association between ovarian dermoid cyst (teratoma) and endometrioma. We retrospectively, included 315 women with endometrioma and 172 with ovarian teratoma. Data were collected from medical and pathological reports from two different areas between 1995 and 2018. The mean age of cases with endometrioma was similar (35.8 \pm 7.2 years) to patients with ovarian teratoma (34.2 \pm 6.8 years). Considering the types of dermoid cysts, the observed proportion of mature type was $168 / 172$ (98\%), the immature type was 4/172 (2\%) and struma ovarii was14/172 $(8.1 \%)$ respectively. Endometrioma was significantly more frequent in the left ovary [174/266 (65.4\%)] than in the right ovary [92/266 (34.6\%)], $\mathrm{P}<0.001$. By contrast, ovarian teratoma were predominant in the right ovary, 98/172 (60.6\%), compared to the left side, 56/172 (32.5\%), $\mathrm{P}<0.001$. Regarding the size of the masses, we detected an inverse distribution between the two groups. Thirteen women were detected with ovarian teratoma and endometriosis, with 6 cases being in the same ovary. Our results indicate a left lateral predispostion of endometrioma and a right of ovarian teratoma and suggest that the pathogenesis between these conditions is different. The coexistence of endometriosis with dermoid cyst of the ovary, presents a challenge to the
\end{abstract}

Correspondence to: Dr Michail Matalliotakis, Department of Obstetrics and Gynecology, Venizeleio and Pananio General Hospital of Heraklion, Knossos Avenue, Heraklion 71409, Greece E-mail: mihalismat@hotmail.com

Key words: endometriosis, endometrioma, ovarian teratoma physicians and the investigators. Further research is required to establish the relationship between endometriosis and ovarian teratoma.

\section{Introduction}

Endometriosis is a benign, yet common gynecological disorder, affecting up to $10 \%$ of the female population of reproductive age, causing considerable pain and infertility. Different forms of endometriosis can be distinguished including peritoneal, ovarian and deep pelvic endometriosis. Ovarian endometriomas are found in 15-42\% of women suffering from endometriosis and are correlated to $35 \%$ of cases of benign ovarian cysts requiring surgery $(1,2)$. Treatment of endometrioma should focus on the relief of symptoms and preservation of future fertility. Thus, operative laparoscopy is considered to be the gold standard choice for the treatment of ovarian endometrioma $(3,4)$.

Interestingly, Tsolakidis et al (4) reported a higher recurrence rates in women who underwent the three-step procedure as contrasted with no recurrence in the cystectomy cases. Mature cystic teratoma, originating from germinal tissue (dermoid cyst), commonly appears in the reproductive age, account for $10-20 \%$ of all ovarian cysts and represent a cavity filled with fatty tissue, hair and/or neuroectodermal and neural crest, usually covered by skin with dermal appendages $(5,6)$. Teratomas, habitually named dermoid cyst, predominantly occur in young women. Of note, in a recent study, Coy et al (7) observed that mature teratomas are the most frequent ovarian masses, accounting for almost $50 \%$ of ovarian tumors, arising from all three germ-cell layers (ectoderm, mesoderm and endoderm). Importantly, early studies, based on chromosome and enzyme data from ovarian teratomas have provided evidence of heterogeneous origin (8). Other studies using analyses of isozyme, HLA, DNA and cytogenetic markers have shown that most ovarian teratomas arise due to defective meiotic 
processes (9). Thus, apart from the mentioned germ cell origin, arising in a number of different ways, somatic cell origin or an origin from a blastomere that was an identical twin of the patient has also been. Although most teratomas have a typical 46,XX karyotype (10), mosaicism has been also found in some (11). Chromosomally abnormal teratomas have been revealed, including trisomy, double trisomy and tetrasomy (12). Mature cystic teratomas of the ovary may be identified by routine physical examination, during radiographic examinations, or during abdominal surgery performed for other causes (13).

We have previously reported in a group of 1,000 women that endometriosis can coexist with several types of benign gynecological masses (2). The small number of case reports and series published thus far, prompted us to analyze the clinicopathological data among patients with ovarian endometrioma in comparison to teratoma. In the framework of this study, we further investigated the association between these two conditions.

\section{Patients and methods}

In the present study, we conducted a retrospective chart review including 172 women with ovarian teratoma and 313 cases with endometrioma. Patient information was obtained from medical, operative and pathology reports. The records of all the patients with endometrioma that were treated at Yale University Hospital (New Haven, USA) from 1995 to 2005, at the Obstetrics and Gynecology Department of the University Hospital (1995-2015) and Venizeleio and Panionio General Hospital of Crete (Heraklion, Greece) from 1995 to 2018 , were reviewed. In total, 315 women with endometrioma who underwent surgical treatment by laparoscopy or laparotomy were investigated. The stage of endometriosis was scored according to the revised classification of the American Fertility Society (14). Moreover, we studied 172 patients with teratoma. The data regarding ovarian teratoma were collected by clinicians and pathologists from the Greek institutes.

The clinicopathological characteristics of the teratoma were further classified as previously described (15). Data were recorded including age, symptoms, side (left or right), size and types of teratoma. Additionally, the information of the histological type of teratoma was obtained from pathological records.

The Human Committee of Yale University School of Medicine approved the study for this evaluation (HIC no. 12590). The Ethics Committee for Human Research of Venizeleio Hospital also approved the study (ECHR no. 46/6686, 47\#773/2017). All the patients provided informed consent prior to participation. The results are reported as the means \pm standard deviation (SD) or as percentages $(\%)$ where appropriate. The frequency of leftand right-sided predisposition was analyzed using the $\chi^{2}$ test. $\mathrm{P}<0.05$ was considered to indicate a statistically significant difference.

\section{Results}

The mean age of patients with teratoma was $34.2 \pm 6.8$ and $35.8 \pm 7.2$ years of age of endometrioma cases, respectively.
Various indications for surgery were detected and are presented in Tables I and II. The main complaints were pelvic pain and/or a palpable adnexal mass for teratoma and infertility and pelvic pain for endometrioma. Other characteristics of patients with ovarian teratoma are presented in Table I. Mature teratoma was found in $98 \%$ and immature in $2 \%$ of cases. Moreover, struma ovarii was confirmed in $8.1 \%$ of all women.

Analysis of patients according to the site and size of teratoma and endometrioma are shown in Tables I and II). In ovarian teratoma group, left-sided mass was detected in $32.5 \%(56 / 172)$ of women, which was significantly lower compared to right-sided mass $(98 / 172,57 \%, \mathrm{P}<0.001)$. The patients with endometrioma had inverse results (Table II). Left-sided cysts were recorded in $65.4 \%$ (174/266) of cases, which was significantly higher compared to the right-sided cysts $(99 / 266,34.6 \%, \mathrm{P}<0.001)$. Regarding the size of teratoma, 56 cysts were $>10 \mathrm{~cm} ; 8$ (14\%) of which were left-sided and 48 (39\%) were right-sided $(\mathrm{P}<0.01)$. By contrast, regarding endometrioma size, 114 cysts were $>5 \mathrm{~cm}$, with $79(45 \%)$ of these being left-sided and 35 (38\%) being right-sided $(\mathrm{P}<0.02)$.

The co-existence of ovarian teratoma with endometriosis detected in $4.6 \%(8 / 172)$ of women and with endometrioma in $2.9 \%(5 / 172)$ (Table I). We found 6 cases where endometriosis coexisted with mature cystic teratoma in the same ovary ( 2 cases of endometrioma and teratoma, 2 cases of endometriosis and teratoma, 1 case of struma ovarii and endometrioma and 1 case of bilateral teratoma and endometriosis) (data not shown).

\section{Discussion}

Previous studies have suggested that a co-morbidity association exists between endometriosis and several benign gynecological tumors $(2,5,16-18)$. In particular, there are various reports regarding the co-morbidity of ovarian teratoma and endometriosis (2,6,7,19-21). Ovarian teratomas were documented as early as the 17 th century. A PubMed search of the literature with keyword endometriosis yielded a total number of 24,819 papers. Using the combination of teratoma and endometriosis, it turned up $224(0.9 \%)$ of the total literature (accessed on March 2018).

According to the literature, in large cohort of patients, ovarian dermoid cyst had a predisposition to a right lateral location (22). Apart from that, it has also been reported that ovarian endometriomas are associated with more pain compared to ovarian teratomas, suggesting that, pain from ovarian endometriomas may be a consequence of the endometrial tissue lesions (21). In the current study, we found that unilateral endometrioma was prominent on the left-sided $(65.4 \%)$ than the right-sided $(34.6 \%)$ ovary. In contrast, we detected that unilateral teratoma was more frequent on the right-side $(60.6 \%)$ cyst, compared to the left-side $(32.5 \%)$ one. Moreover, regarding the size of the mass, we confirmed inverse results. Teratoma size was prominent in the right side and endometrioma in the left size. Our results are in agreement with those of our previous studies $(2,23)$.

The combination of the female varicocele and retrograde menstruation theories could play a major role in the creation of ovarian endometriosis or endometrioma. These and previous 
Table I. Clinical characteristics and lateral distribution of teratoma in 172 women $^{\mathrm{a}}$.

\begin{tabular}{|c|c|}
\hline Variables & Values \\
\hline Age (years) & $34.2 \pm 6.8$ \\
\hline Range & $17-60$ \\
\hline \multicolumn{2}{|l|}{ Indication for surgery } \\
\hline Infertility & $22 / 172(13 \%)$ \\
\hline Pelvic pain & $57 / 172(33 \%)$ \\
\hline Adnexal mass & $93 / 172(54 \%)$ \\
\hline \multicolumn{2}{|l|}{ Types } \\
\hline Mature & $168(98 \%)$ \\
\hline Immature & $4(2 \%)$ \\
\hline Struma ovarii & $14(8.1 \%)$ \\
\hline \multicolumn{2}{|l|}{ Right and left hemi pelvis (location) } \\
\hline \multicolumn{2}{|l|}{ Size (diameter) in centimeter $(\mathrm{cm})$} \\
\hline Left-sided & $\begin{array}{c}56(32.5 \%) \\
1-10 \mathrm{~cm}=48(86 \%),>10 \mathrm{~cm}=8(14 \%)\end{array}$ \\
\hline Right-sided & $\begin{array}{c}98(57 \%) \\
1-10 \mathrm{~cm}=60(61 \%),>10 \mathrm{~cm}=48(39 \%)\end{array}$ \\
\hline Bilateral cysts & $\begin{array}{c}18(10,5 \%) \\
1-10 \mathrm{~cm}=14(78 \%),>10 \mathrm{~cm}=4(22 \%)\end{array}$ \\
\hline \multicolumn{2}{|l|}{ Associated with } \\
\hline Endometriosis & $8(4.6 \%)$ \\
\hline Endometrioma & $5(2.9 \%)$ \\
\hline Adenomyosis & $11(6.4 \%)$ \\
\hline Uterine leiomyoma & $19(11 \%)$ \\
\hline Adenomyosis and leiomyoma & $8(4.6 \%)$ \\
\hline Other benign ovarian conditions & $21(12.2 \%)$ \\
\hline Uterine cancer & $3(1.7 \%)$ \\
\hline
\end{tabular}

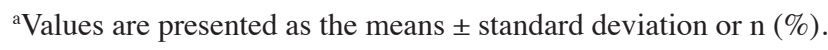

results are in accordance with those of other studies (5,24-26), where the teratoma is more frequently appeared on the left side because of the anatomical position of sigmoid colon, which is in direct contact with the left adnexa and occasionally fixed to the left pelvic brim by firm adhesions. In particular, this anatomic relationship may prevent the refluxed fragments of endometrial tissue through the left fallopian tube from following the intra-abdominal clockwise movement of peritoneal fluid and thus would enable the adhesion and growth of the endometrial tissue on the left pelvic site. Apart from that, when endometriosis is found only on the right side the possibility of recurrence is less and the interval between operation and conception seems to be minor compared to the involved left hemi pelvis (27). In cases with teratoma, the observed proportion of right side was higher than that in the left side, suggesting a distinct pathogenesis of the two entities. In 2000, Vercellini et al (5) postulated that dermoid cysts have a different pathogenesis from that of endometrioma.

Although the genetics of endometriosis are very well studied (28-31), genetic analyses of ovarian teratoma remain poor. Familial cases of ovarian teratoma are very rare and only 10 teratoma have been described thus far (32-35). In all these cases, a dominant mode of inheritance has been identified but no causative or predisposing genes have been reported. By using short tandem repeat analysis based on 6 markers (D20S480, D6S2439, D6S1056, D9S1118, D4S2639 and D17S1290), it became possible to distinguish the germ cell or somatic origin of ovarian cystic teratomas (36). Notably, three gene loci, namely FGA,D21S11 and D19S433 have been found to exhibit a significant loss of heterozygosity, mostly likely due to the participation of their protein products in the development of mature cystic teratomas of the uterus (37). Moreover, varying degrees of hypermethylation of SNRPN gene and $K v D M R$ but not H19DMR locus were found in the presence of maternal uniparental disomy in several cystic teratomas of the ovary examined (38). Recently, in a study aiming to shed light on the mechanism regarding how endometriomas become more adherent to ovarian tissues compared with teratomas, it was found that the cystic walls of endometriomas exhibited obvious fibrosis compared with mature teratomas and endometriotic cells synthesized TGF- $\beta 1$, a critical factor that promotes fibrosis formation (39).

To the best of our knowledge, few cases of endometriosis coexist with dermoid cyst in a single ovary $(7,19,20,40)$. This is the first study involving 172 women with dermoid 
Table II. Clinical characteristics and lateral distribution of endometrioma in 315 women $^{\text {a }}$.

\begin{tabular}{lc}
\hline Variables & Values \\
\hline Age (years) & $35.8 \pm 7.2$ \\
Range & $19-52$ \\
Indication for surgery & $145 / 315(46 \%)$ \\
Infertility & $131 / 315(42 \%)$ \\
Pelvic pain & $39 / 315(12 \%)$ \\
Adnexal mass & \\
Right and left hemi pelvis (location) & \\
Size (diameter) in cm & $174(65.4 \%)$ \\
Left-sided & $1-5 \mathrm{~cm}=95(55 \%)$ \\
& $>5 \mathrm{~cm}=79(45 \%)$ \\
& $92(34.6 \%)$ \\
Right-sided & $1-5 \mathrm{~cm}=57(62 \%)$ \\
& $>5 \mathrm{~cm}=35(38 \%)$ \\
$49(16 \%)$ \\
Bilateral & $1-5 \mathrm{~cm}=29(59 \%)$ \\
& $>5 \mathrm{~cm}=20(41 \%)$ \\
\hline
\end{tabular}

${ }^{\text {a } V a l u e s ~ a r e ~ p r e s e n t e d ~ a s ~ t h e ~ m e a n s ~} \pm$ standard deviation or $\mathrm{n}(\%)$.

cysts and the simultaneous co-existence of 13 cases with endometriosis or endometrioma. We found 6 patients with dermoid cyst and endometriosis or endometrioma in the same ovary. In conclusion, our retrospective work confirms two major findings. First, we present a left lateral predisposition of endometrioma and a right lateral predisposition of teratoma, and support that the pathogenesis in this two diseases is different. The second finding deals with the co-morbidity of cases with teratoma and endometriosis. Although the pathophysiology of endometriosis and teratoma is enigmatic and not fully understood, and given the rarity of the co-existence of ovarian endometrioma and teratoma, the current study represents a challenge to clinicians and pathologists for further research in order to elucidate the correlation between these two conditions as well as for a better diagnosis and treatment by combining radiological, clinical and biological approaches.

\section{Acknowledgements}

The authors would like to thank all the clinicians and the pathologists for providing the data and pathology reports in this study.

\section{Funding}

No funding was received.

\section{Availability of data and materials}

The datasets used and/or analyzed during the current study are available from the corresponding author on reasonable request.

\section{Authors' contributions}

MM and IM conceived and designed the study. AA, CM, KK, IK and IM obtained the data. MM, GNG, MIZ, CM, and DAS analysed and interpreted the data. MIZ, MM and CM drafted the manuscript. MM, GNG, KK, IM, AA and DAS critically revised the manuscript. All authors have read and approved the manuscript.

\section{Ethics approval and consent to participate}

The Human Committee of Yale University School of Medicine approved the study for this evaluation (HIC no. 12590) and the Ethics Committee for Human Research of Venizeleio Hospital has approved the respective protocol (ECHR no. 46/6686). Informed consent was obtained from all the participants

\section{Patienta consent for publication}

Not applicable.

\section{Competing interests}

DAS is the Editor-in-Chief for the journal, but had no personal involvement in the reviewing process, or any influence in terms of adjudicating on the final decision, for this article.

\section{References}

1. Zanelotti A and Decherney AH: Surgery and endometriosis. Clin Obstet Gynecol 60: 477-484, 2017.

2. Matalliotaki C, Matalliotakis M, Ieromonachou P, Goulielmos GN, Zervou MI, Laliotis A, Spandidos DA, Arici A and Matalliotakis I: Co-existence of benign gynecological tumors with endometriosis in a group of 1,000 women. Oncol Lett 15: 1529-1532, 2018.

3. Alborzi S, Hosseini-Nohadani A, Poordast T and Shomali Z: Surgical outcomes of laparoscopic endometriosis surgery: A 6 year experience. Curr Med Res Opin 33: 2229-2234, 2017.

4. Tsolakidis D, Pados G, Vavilis D, Athanatos D, Tsalikis T, Giannakou A and Tarlatzis BC: The impact on ovarian reserve after laparoscopic ovarian cystectomy versus three-stage management in patients with endometriomas: A prospective randomized study. Fertil Steril 94: 71-77, 2010.

5. Vercellini P, Pisacreta A, Vicentini S, Stellato G, Pesole A and Crosignani PG: Lateral distribution of nonendometriotic benign ovarian cysts. BJOG 107: 556-558, 2000.

6. Chiang AJ, Chen DR, Cheng JT and Chang TH: Detection of human papillomavirus in squamous cell carcinoma arising from dermoid cysts. Taiwan J Obstet Gynecol 54: 559-566, 2015.

7. Coy S, Meserve E, Berkowitz R and Hirsch MS: De novo tumors of teratoma: Ganglioneuroma arising from a mature cystic teratoma of the ovary. Int J Gynecol Pathol 37: 296-300, 2018.

8. Parrington JM, West LF and Povey S: The origin of ovarian teratomas. J Med Genet 21: 4-12, 1984.

9. Deka R, Chakravarti A, Surti U, Hauselman E, Majumder PP and Ferrell RE: Genetics and biology of human ovarian teratomas. II. Molecular analysis of origins and gene-centromere distance of chromosome I markers. Am J Hum Genet 47: 644-655, 1990.

10. Corfman PA and Richart RM: Chromosome number and morphology of benign ovarian cystic teratomas. N Engl J Med 271: 1241-1244, 1964.

11. Patil SR, Kaiser-McCaw B, Hecht F, Linder D and Lovrien EW: Human benign ovarian teratomas: Chromosomal and electrophoretic enzyme studies. Birth Defects Orig Artic Ser 14 (6B): 297-301, 1978.

12. Surti U, Hoffner L, Chakravarti A and Ferrell RE: Genetics and biology of human ovarian teratomas. I. Cytogenetic analysis and mechanism of origin. Am J Hum Genet 47: 635-643, 1990. 
13. Stany MP and Hamilton CA: Benign disorders of the ovary. Obstet Gynecol Clin North Am 35: 271-284, ix, 2008.

14. American Society for Reproductive Medicine: Revised American Society for Reproductive Medicine classification of endometriosis: 1996. Fertil Steril 67: 817-821, 1997.

15. Russell P: Surface epithelial-stromal tumors of the ovary. In: Blaustein's Pathology of the Female Genital Tract. Kurman RJ (ed). 4th edition. Springer-Verlag, New York, NY, pp705-782, 1994

16. Mahnert N, Morgan D, Campbell D, Johnston C and As-Sanie S: Unexpected gynecologic malignancy diagnosed after hysterectomy performed for benign indications. Obstet Gynecol 125: 397-405, 2015.

17. Verit FF and Yucel O: Endometriosis, leiomyoma and adenomyosis: The risk of gynecologic malignancy. Asian Pac J Cancer Prev 14: 5589-5597, 2013

18. Choi EJ, Cho SB, Lee SR, Lim YM, Jeong K, Moon HS and Chung H: Comorbidity of gynecological and non-gynecological diseases with adenomyosis and endometriosis. Obstet Gynecol Sci 60: 579-586, 2017

19. Chen TC, Kuo HT, Shyu SK, Chu CP and Chang TC: Endometriosis coexisting with dermoid cyst in a single ovary: A case report. Chin Med J (Engl) 124: 627-630, 2011.

20. Chae $\mathrm{H}$ and Rheu $\mathrm{C}$ : Endometriosis coexisting with mature cystic teratoma in the same ovary and ectopic pregnancy of left fallopian tube: A rare coexistence. Clin Case Rep 3: 315-318, 2015.

21. Chmaj-Wierzchowska KS, Kampioni M, Wilczak M, Sajdak S and Opala T: Assessment of pain and stress intensity among women with ovarian endometriomas versus teratomas. Pain Res Manag 20: 133-136, 2015.

22. Al-Fozan H, Glassman J, Caspi B, Appelman Z and Tulandi T: Lateral distribution of ovarian dermoid cyst. J Am Assoc Gynecol Laparosc 10: 489-490, 2003.

23. Matalliotakis IM, Cakmak H, Koumantakis EE, Margariti A, Neonaki M and Goumenou AG: Arguments for a left lateral predisposition of endometrioma. Fertil Steril 91: 975-978, 2009.

24. Jenkins S, Olive DL and Haney AF: Endometriosis: Pathogenetic implications of the anatomic distribution. Obstet Gynecol 67: 335-338, 1986

25. Vercellini P, Aimi G, De Giorgi O, Maddalena S, Carinelli S and Crosignani PG: Is cystic ovarian endometriosis an asymmetric disease? Br J Obstet Gynaecol 105: 1018-1021, 1998.

26. Al-Fozan $\mathrm{H}$ and Tulandi T: Left lateral predisposition of endometriosis and endometrioma. Obstet Gynecol 101: 164-166, 2003.

27. Ghezzi F, Beretta P, Franchi M, Parissis M and Bolis P: Recurrence of ovarian endometriosis and anatomical location of the primary lesion. Fertil Steril 75: 136-140, 2001.

28. Zondervan KT, Becker CM, Koga K, Missmer SA, Taylor RN and Viganò P: Endometriosis. Nat Rev Dis Primers 4: 9, 2018.

29. Nyholt DR, Low S-K, Anderson CA, Painter JN, Uno S, Morris AP, MacGregor S, Gordon SD, Henders AK, Martin NG, et al: Genome-wide association meta-analysis identifies new endometriosis risk loci. Nat Genet 44: 1355-1359, 2012.
30. Sapkota Y, Steinthorsdottir V, Morris AP, Fassbender A, Rahmioglu N, De Vivo I, Buring JE, Zhang F, Edwards TL, Jones S, et al; iPSYCH-SSI-Broad Group: Meta-analysis identifies five novel loci associated with endometriosis highlighting key genes involved in hormone metabolism. Nat Commun 8: 15539, 2017.

31. Matalliotakis M, Zervou MI, Eliopoulos E, Matalliotaki C, Rahmioglu N, Kalogiannidis I, Zondervan K, Spandidos DA, Matalliotakis I and Goulielmos GN: The role of IL 16 gene polymorphisms in endometriosis. Int J Mol Med 41: 1469-1476, 2018.

32. Hecht F, McCaw BK and Patil S: Ovarian teratomas and genetics of germ-cell formation. Lancet 2: 1311, 1976 .

33. Simon A, Ohel G, Neri A and Schenker JG: Familial occurrence of mature ovarian teratomas. Obstet Gynecol 66: 278-279, 1985.

34. Gustavson KH and Rune C: Familial ovarian dermoid cysts. Ups J Med Sci 93: 53-56, 1988.

35. Nezhat C, Kotikela S, Mann A, Hajhosseini B, Veeraswamy A and Lewis M: Familial cystic teratomas: Four case reports and review of the literature. J Minim Invasive Gynecol 17: 782-786, 2010.

36. Fujii K, Yamashita Y, Yamamoto T, Takahashi K, Hashimoto K, Miyata T, Kawai K, Kikkawa F, Toyokuni S and Nagasaka T: Ovarian mucinous tumors arising from mature cystic teratomas-a molecular genetic approach for understanding the cellular origin. Hum Pathol 45: 717-724, 2014.

37. Wang WC, Lee MS, Ko JL and Lai YC: Origin of uterine teratoma differs from that of ovarian teratoma: A case of uterine mature cystic teratoma. Int J Gynecol Pathol 30: 544-548, 2011

38. Wang WC and Lai YC: Genetic analysis results of mature cystic teratomas of the ovary in Taiwan disagree with the previous origin theory of this tumor. Hum Pathol 52: 128-135, 2016.

39. Shi LB, Zhou F, Zhu HY, Huang D, Jin XY, Li C, Dai Y, Pan YB and Zhang SY: Transforming growth factor betal from endometriomas promotes fibrosis in surrounding ovarian tissues via Smad2/3 signaling. Biol Reprod 97: 873-882, 2017.

40. Hwang JY, Lee MH, Lee JH, Kim DH and Song SH: A case of unilateral endometriosis coexisting with struma ovarii in bilateral ovarian teratoma. J Minim Invasive Gynecol 25: 941-943, 2018.

This work is licensed under a Creative Common Attribution-NonCommercial-NoDerivatives 4.0 International (CC BY-NC-ND 4.0) License. 